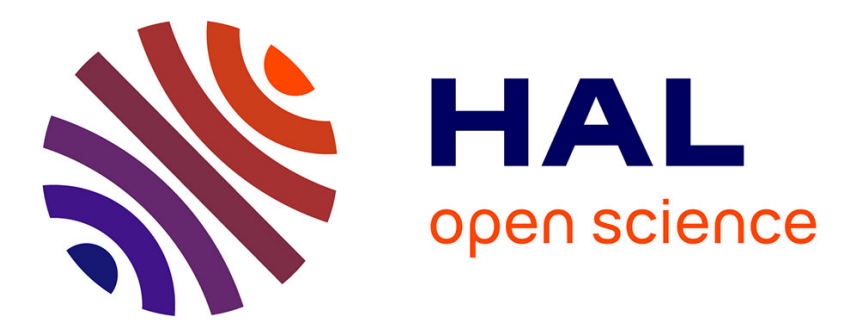

\title{
Mariages : les villes répulsives, les territoires ruraux plébiscités
}

Gérard-François Dumont

\section{To cite this version:}

Gérard-François Dumont. Mariages : les villes répulsives, les territoires ruraux plébiscités. Population et avenir, 2012, J307D-709, pp.3. 10.3917/popav.709.0003 . halshs-00836033

\section{HAL Id: halshs-00836033 \\ https://shs.hal.science/halshs-00836033}

Submitted on 20 Jun 2013

HAL is a multi-disciplinary open access archive for the deposit and dissemination of scientific research documents, whether they are published or not. The documents may come from teaching and research institutions in France or abroad, or from public or private research centers.
L'archive ouverte pluridisciplinaire HAL, est destinée au dépôt et à la diffusion de documents scientifiques de niveau recherche, publiés ou non, émanant des établissements d'enseignement et de recherche français ou étrangers, des laboratoires publics ou privés. 


\section{Mariages :}

\section{les villes répulsives, les territoires ruraux plébiscités}

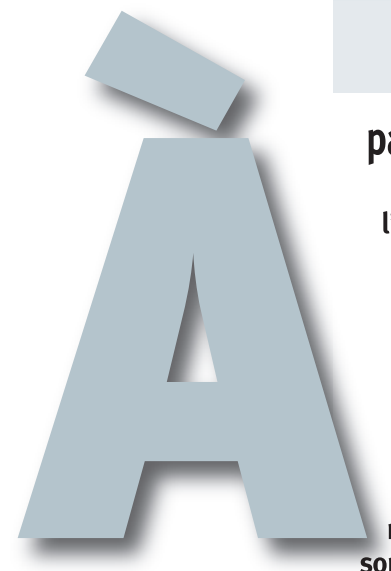

par Gérard-François DUMONT

l'heure de l'urbanisation, la majorité des jeunes de France vit dans les villes. Aussi les départements urbains ont-ils une proportion élevée de personnes en âge de se mettre en couple, disons entre 20 et 35 ans. Mais, lorsqu'il s'agit de se marier, c'est une autre affaire. Pour nombre de couples, le territoire de mariage ne doit pas être la ville où ils sont domiciliés, mais un département rural d'où est originaire une partie de l'une ou l'autre des familles. Il y a ainsi des départements répulsifs dont les couples ne veulent pas utiliser les salles de mariage et des départements attractifs qui sont privilégiés, où le mariage représente une véritable activité économique.

En France, l'enregistrement des mariages s'effectue dans la commune où le mariage est célébré. Normalement, les mariages sont célébrés dans la commune où l'un des futurs époux est domicilié ou s'il y détient une résidence continue établie depuis plus d'un mois. Cette notion de résidence s'étend en réalité à une résidence des parents qui peut être principale ou secondaire. II en résulte une certaine liberté de choix dans la mairie du lieu du mariage. D'ailleurs, les couples ne s'en privent pas et nombre d'entre eux excluent de choisir comme mairie de mariage l'une de celles du département où ils sont domiciliés.

\section{Les départements urbains répulsifs}

Les départements les plus répulsifs sont des départements urbains. Le record est détenu par Paris. Pour la dernière année disponible, le nombre de couples domiciliés dans ce département et qui se sont mariés est de 12078 . Mais $22 \%$ de ces couples, 2640 exactement, ont choisi d'aller se marier dans une mairie d'un autre département. Après Paris, les autres départements répulsifs sont ceux où le taux de population urbaine ${ }^{1}$ est le plus élevé. L'on trouve ainsi parmi les dix départements les plus répulsifs tous ceux de la région Île-de-France, à l'exception de la Seine-et-Marne, le département le moins urbain de cette région. Les trois autres départements les plus répulsifs ${ }^{2}$ ont un fort taux d'urbanisation : le Rhône, la Haute-Garonne et les Bouches-du-Rhône.

\section{Le mariage, une activité économique dans des départements ruraux}

À l'inverse, les couples qui habitent dans les villes privilégient, parmi les facteurs de choix d'une mairie de mariage, le charme d'un département rural dont est originaire l'une des familles. Toujours pour la dernière année disponible, le record, en proportion, des mariages enregistrés, est détenu par la Lozère. Ce département compte 271 mariages enregistrés mais, parmi les couples concernés, seuls 204 y sont domiciliés. Donc $24,7 \%$
1. LES DÉPARTEMENTS RÉPULSIFS, OÙ LES COUPLES HABITENT

MAIS N'AIMENT PAS S'Y MARIER

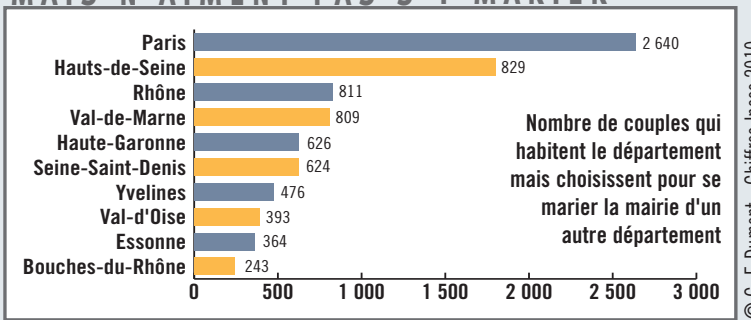

2. LES DÉPARTEMENTS ATTRACTIFS, OÙ LES COUPLES NON DOMICILIÉS

\section{CHOISISSENT DE SE MARIER}

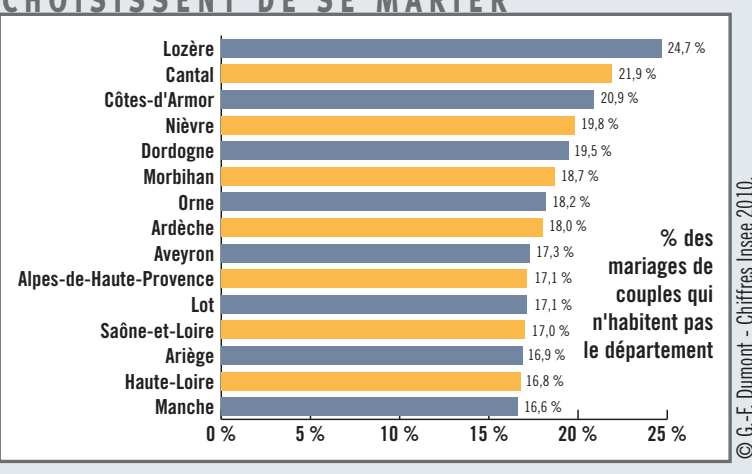

1. Ce taux est le rappot de ta population cumulée des communes dites urbaines sur la population totale (« municipale » selon la terminologie de a loi de 2002) du département. Cf. Dumont, GérardFrancois (direction), La France en villes, Paris, Sedes.

Leur caractère répulsif serait sans doute plus élevé si 'on pouvait connaître parmi les mariages civils domiciliés les mariages civils domicilies dens departements ubains, ceux qui organisent un mariage religieux et les festivités qui le suivent dans un département rural.

3. Une nouvelle preuve de l'erreur d'avoir éliminé l'adjectif rural dans le zonage en aires urbaines des territoires franÇais. Cf. « Un meurtre géographique : la France rurale ", Population \& Avenir, $n^{\circ} 707$ mars-avil 2012.

4. On pourrait aussi dire que, pour le mariage, le territoire emporte sur la ville (cf. Beauchard, Jacques « Une révolution dans l'espace français : ville contre le territoire? », Population \& Avenir, no 708 mai-jin 2012).

des mariages dans des mairies de Lozère, 67 exactement, concernent des couples domiciliés hors de ce département. Après la Lozère, les proportions les plus élevées se constatent dans le Cantal, dans les Côtes d'Armor... La liste des départements où plus de $16 \%$ des mariages enregistrés concernent des couples domiciliés dans un autre département correspond aux départements dont le taux de population rurale est le plus élevé. Les couples montrent ainsi leur attachement à la ruralité ${ }^{3}$ même lorsque leur vie se déroule en ville ${ }^{4}$. Et comme les mariés ou leurs parents invitent des parents ou amis à venir dans le département rural de la mairie du mariage, mariage qui s'accompagne normalement de réjouissances, cela peut représenter, notamment pour l'hôtellerie et la restauration, une vraie activité économique.

C'est même une activité économique qui, globalement pour la France, est excédentaire. En effet, la France enregistre 3352 mariages de couples qui ne sont domiciliés ni en France métropolitaine, ni dans les départements d'outre-mer et qui résident donc à l'étranger. Il apparaît ainsi que des Français qui vivent à l'étranger préfèrent célébrer leur mariage en France plutôt qu'à l'étranger. Voici une excellente nouvelle pour la balance du commerce extérieur. Une nouvelle qui pourrait être encore meilleure si un territoire français se transformait en un Las Vegas du mariage!

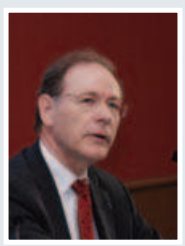

